\title{
Optimization of Loadometer Allocation with Internet of Things in Bulk Port
}

\author{
Lei Huang ${ }^{1}$ and Yi Guo ${ }^{1 *}$ \\ ${ }^{1}$ School of Economics \& Management, Beijing Jiaotong University, \\ Beijing, China, 100044 \\ lhuang@bjtu.edu.cn;11113164@bjtu.edu.cn
}

\begin{abstract}
Traditional resources allocation in port usually use queuing model and has deviations between model and actual situation. In this paper, focus on loadometers allocation in bulk port, we propose an optimization solution with Internet of Things. Primary method of this solution is upgrading devices with RFID technology. This solution provides more efficiencies and accuracies cause of reducing manual works and collecting dynamic parameters for queuing model. This paper also shows a simple case study of bulk port in southern China.
\end{abstract}

Keywords: Bulk port, loadometers allocation, Internet of Things, Queuing model

\section{Introduction}

Compared with the container port, bulk port is more complex. Bulk cargo use more than 15 kinds of package methods and have no uniform standard [1]. Even more, many bulk cargo such as coal, ore and bulk cereal, cannot be identified uniquely like container. That's a major reason of the automation management level of bulk port is lagged behind the container port.

In bulk port, there are several activities between ships arrival to cargo clearance. Loadometers allocation is an important link among these activities. It usually use queuing model to predict the allocation of loadometers. Cause of parameters' deviations, the predicted allocation need to adjust by manual work that matching actual situations. That costs much more time and manual works, reduces the efficiency of port operation.

With matures and industrialization of RFID technology, dynamically collect vehicle information and allocate loadometer resources is no longer distant. By using RFID technology to upgrade port devices, bulk port can get rid of the traditional distress, achieve a higher automation management level similar to container port [5].Hence, we believe in the help of RFID, loadometers allocation can be more efficiency and accuracy than manual management.

\section{Related Work}

RFID is the abbreviation of Radio Frequency Identification. It uses radio frequency waves to transfer data between readers and tags that realizing auto identify. It is regarded as an important technology helps enterprise to improve performance, and it plays a major role in Internet of Things. The utilization of RFID brings new opportunity to logistics [17]. That will gain innovation and flexibility to supply chain to keep competitive advantage [11].

RFID has been successfully utilized in logistics, supply chain management and manufacturing. Benefits from utilizing RFID in port include supply chain management efficiencies and tracking the whole process real-time [6, 10, 12]. RFID technology can 
increase accuracy, efficiency and speed of processes. It can also reduce storage and handling and distribution costs [16].

As Jedermann et al., predicted [7], using RFID-tag will be standard in logistics. Many authors have proposed the impacts and applications on supply chain with RFID [2, 15, 19, 24]. Xiaoning Shi et al., represent a RFID application in container port [18]. Wenjie Wang et al., take a case study on Shanghai Port [25]. Siror, J. K. et al., proposed an intelligent port model to minimize reliance on manual interventions and controls [19]. Song Xin and Huang Lei represented an optimization and system design of bulk port based on IoT [20].

Queuing theory is the study of the mathematical theory and the methods of queuing systems is an important branch of operations research [8]. It is usually used in resource planning and allocation. Munisamy, S proposed a capacity planning of timber port with queuing theory. It is used in forecast the port's throughout capacity that provided guidance for port authorities and port operators [14].Legato, P. and Mazza, R. M. provide a solution based on non-standard service stations, time-dependent priority mechanisms and complex resource allocation policies to allocate resources for vessels arriving, berthing and departure [9]. Bugaric, U. et al., used queuing theory to estimate capacity of unloading in bulk port [4]. Bugaric, U. S et al., used queuing theory to optimize unloading service in bulk port [3]. Vehicles arrive at port and wait for weigh by loadometer can also be seen as a queuing model that the loadometer resources should be allocated.

\section{Loadometers Allocation with Queuing Models}

There is often exist an imbalance in port weigh activities, the imbalance is caused by many factors, such as the number of loadometers, the delay of information transfer, the surge of collection and distribution. Once vehicle entries port, port cannot get any information until the vehicle reach loadometers. So as to guarantee operation smoothly while maintaining low cost, port generally predict with using queuing models to determine how many loadometers should be used.

Weigh vehicle can be regarded as stochastic service. In stream and service time follow Poisson distribution. So the $\mathrm{M} / \mathrm{M} / \mathrm{n}$ model is usually used in prediction. Cause of inaccurate statistics data or surge of collection and distribution, there usually need to adjust the amount of loadometers in service manually. There is an example on April 30. Service ratio $\mu=15$ vehicles $/ \mathrm{h}$ and arrival rate $\lambda=55$ vehicles $/ \mathrm{h}$ are estimated with the historical data. According to $\mathrm{M} / \mathrm{M} / \mathrm{n}$ queuing model, there are formulas as follow:

$$
\begin{gathered}
p_{0}=\left(\sum_{k=0}^{n-1} \frac{\rho_{1}^{k}}{k !}+\frac{\rho_{1}^{n}}{n !} \frac{1}{1-\rho}\right)^{-1} \\
L_{q}=\frac{\rho_{1}^{n+1} p_{0}}{(n-1) !\left(n-\rho_{1}\right)^{2}} \\
L_{b}=\rho_{1}=\frac{\lambda}{\mu} \\
W_{q}=\frac{L_{q}}{\lambda}=\frac{L_{q}+L_{b}}{\mu n \cdot n !(1-\rho)^{2}}
\end{gathered}
$$




$$
\begin{aligned}
& W_{s}=\frac{L_{s}}{\lambda}=W_{q}+\frac{1}{\mu} \\
& \mathrm{C}\left(n, \rho_{1}\right)=\frac{n p_{n}}{n-\rho_{1}}
\end{aligned}
$$

In these formulas, $p_{0}$ refers to idleness of loadometers; $L_{q}$ refers to average queue length; $L_{b}$ refers to average working loadometers; $L_{s}$ refers to average vehicles in port, which includes both in service and queuing; $W_{q}$ refers to average queuing time; $W_{s}$ refers to average waiting time before weigh and $\mathrm{C}\left(n, \rho_{1}\right)$ refers to the ratio of that vehicles cannot be serviced at once i.e., the ratio of queuing. Using $\mathrm{M} / \mathrm{M} / \mathrm{n}$ queuing model, port calculates a result with different $n$ as Table. 1 shows.

\begin{tabular}{|c|c|c|c|c|c|c|}
\hline parameters $n$ & 4 & 5 & 6 & 7 & 8 & 9 \\
\hline$p_{0}(\%)$ & 0.9 & 2.1 & 2.4 & 2.5 & 2.5 & 2.6 \\
\hline $\mathrm{C}\left(n, \rho_{1}\right)(\%)$ & 82.2 & 43.3 & 21 & 9.3 & 3.8 & 1.4 \\
\hline$L_{q}($ vehicles $)$ & 9.04 & 1.19 & 0.33 & 0.1 & 0.03 & 0.01 \\
\hline$L_{S}($ vehicles $)$ & 12.71 & 4.86 & 4 & 3.77 & 3.7 & 3.68 \\
\hline$W_{q}(\mathrm{~h})$ & 0.16 & 0.02 & 0.006 & 0.002 & 0.0006 & 0.0001 \\
\hline$W_{s}(\mathrm{~h})$ & 0.23 & 0.09 & 0.072 & 0.069 & 0.067 & 0.067 \\
\hline
\end{tabular}

Table 1. Queuing Model Parameter's Value on Apr. 30 with Different $n$

When $n<4$, there has $\rho=\frac{\lambda}{n \mu}>1$ i.e., $\mathrm{M} / \mathrm{M} / \mathrm{n}$ queuing model is unstable, that means vehicles come with the arrival rate $\lambda$ never cannot be weighed at all with the capability of using loadometers. So port listed all results with different available $n$ due to minimum $\rho$ and maximum amount of loadometers in port. Considered to the balance between efficient and cost, port planned to open 5 loadometers. But in actually, there were only 3 loadometers in use and other 2 loadometers is disengaged. That situation was caused by temporary reduction amount of collection and distribution. There were only 729 vehicles came to operate and far below the given $\lambda$.

Despite it is rare that the different between estimate and reality is significant, manual adjustment the allocation of loadometers is general. The dynamic environment of port makes this activity need to be repeated all day with manual work.

Missing dynamic vehicle information and delay of information transmission are bottlenecks in this process that need to be resolved. Cause of the characteristics of Internet of Things, we proposed an optimization solution with RFID and other technologies and devices, which is committed to solve this predicament.

\section{Devices Upgrading with Internet of Tings}

To solve the predicament we mentioned above, we represent an devices upgrading solution correspondingly. There are 4 key points we using in our suggestion as below:

RFID tag binds vehicle uniquely. When vehicle come to port first time, we required it leave record and type vehicle information into port management system. Then bind the RFID tag with corresponding vehicle. This RFID tag is made of ceramic, once driver remove tag themselves, ceramic RFID tag will be broken and can't use any 
more. Cause of this characteristic, mounted RFID tags have become a reliable and unique identification of the operating vehicles, which effectively prevent the counterfeiting vehicle licenses. According to this key point, we intend to deal the problem that bulk cargo is identified hardly with the same method as container ports use. In bulk port, vehicles are used to transit cargo commonly. So identifying vehicles clearly means information of both vehicle and cargo can be found out duly. RFID tag will be associated with operating documents, improve the transmission speed and accuracy of port information [2].

- Handheld tallying with handset. Tallymen handheld tallying can both significantly reduce paper documents and improve inputting efficiency. Furthermore, tally sheet's information can be transferred real time and management system can receive the information about vehicle dynamically. Using handset can also control vehicles onsite effectively. By using handset realize handheld tallying and vehicle control, management and operational staff can master the information and schedule of field operations in time, thereby arrange and adjust port operations plan more targeted.

- Implement unattended loadometer management. With vehicle information and operating information associated with the vehicle-mounted RFID tag, automatically weigh weight and record real-time in order to realize unattended loadometer management. The loadometer members offer remote assistance in the loadometer control room, and supervise vehicle weighing, communicate with on-site person or drivers by intercom at the same time, to resolve unexpected problems whenever necessary. Based on real-time information transmission, management system can open or close loadometers automatically according to traffic flow.

- Intelligent barrier management. To enter the port, RFID reader reads the mounted RFID tag and the vehicle information the tag associated with. If the vehicle record is not in blacklist, the barrier automatically lifts. The using of automatic barrier can reduce manual intervention to improve accuracy and timeliness of in and out checking. With using intelligent barrier, port can calculate the amount of vehicles in port. Port management system can predict recent traffic flow. That also can realize non-stopping in and out checking to improve the efficiency.

\subsection{Intelligent Barrier Retrofitting}

Combined the using of RFID, automatic barrier and the port's existing management system in the transformation of intelligent barrier, intelligent barrier can automatically check vehicles information without stop.

As the Figure 1 shows, there are two sense coils on both sides of the barrier. When operation vehicle prepare entry port, it will trigger the former sense coil. Sense coil sends a signal to activate the antenna. The RFID antenna starts working and receives the mounted RFID tag's signal. This signal includes a unique EPCglobal number that access control subsystem can use this number find out the information of current vehicle and check if the vehicle is allowed to entry. After checking, the LED display shows vehicle information and tips driver can enter port, the barrier automatically lift, allowing vehicle to enter the port and start next process. The state of this vehicle is set to "Entered" in port management system. As vehicle complete all the processes and prepare to departure, the intelligent barrier repeat the same automatic checking. The port management system will set the status as "Departure". These information are collected by port management that use for calculate and predict arrival ratio. 


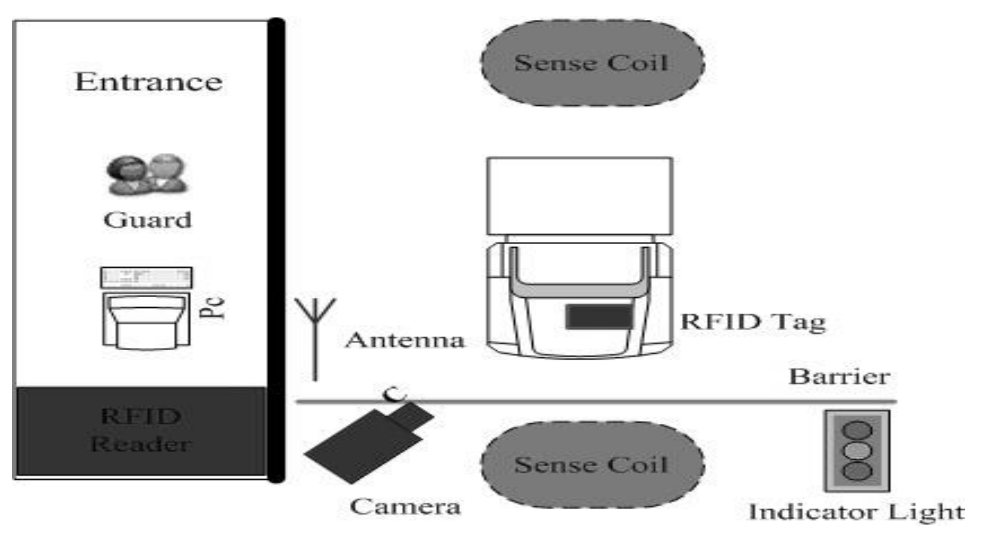

Figure 1. Intelligent Barrier

\subsection{Unattended loadometer Retrofitting}

As Figure 2 shows. Based on the existing loadometer, install RFID reader and antenna, active infrared system, closed-circuit camera monitoring, real-time intercom and LED display, transformed into unattended loadometer. When vehicle drive upon the loadometer, cut off the infrared beam between infrared transmitter and receiver device, the unattended loadometer get into the weighing state. The RFID antenna and reader are open, read the vehicle information and operating information RFID tag associated. The active infrared system monitor vehicle that complete on the loadometer. Vehicle completely stopped, unattended loadometer system automatically records the loadometer reading in the port management system. The LED display shows vehicle operating information and barrier automatically lifts, permitting vehicle start next process. Vehicle completely through the sense coil, the barrier automatically fall that completing the vehicle weighing business process. If there has any problem in the weighing process, the LED display will show tip and reason, the driver can communicate with the loadometer members through the intercom in-time.

Unattended loadometers collect weigh information and transmit to port management system as the basis of service ratio. According to the command from port management system, loadometers can open/close automatically to satisfied need.

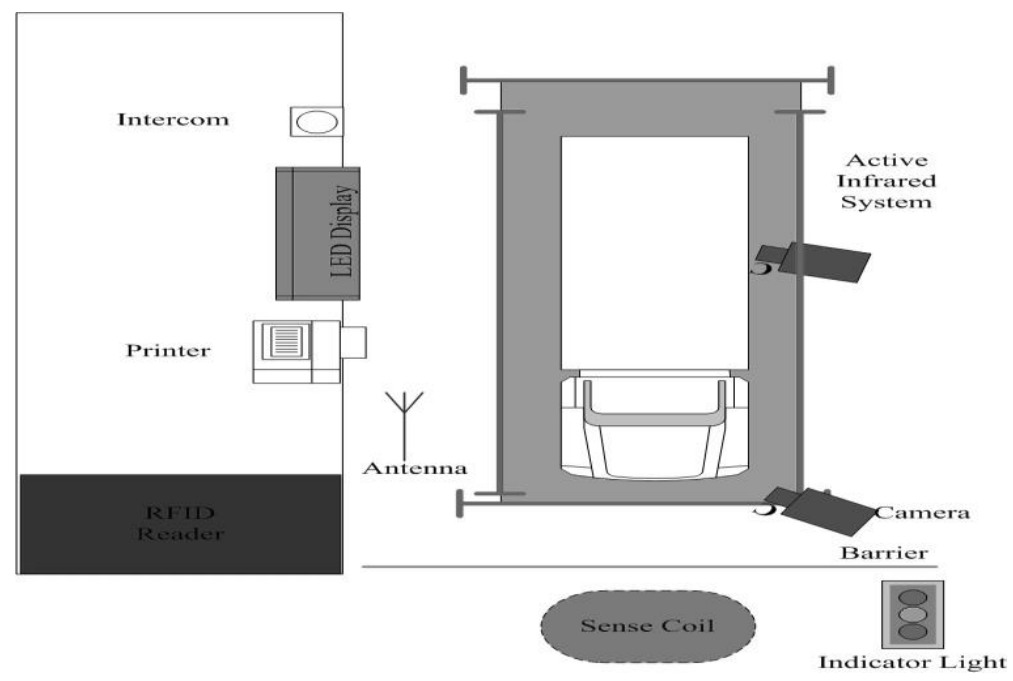

Figure 2. Unattended Loadometer 


\subsection{Handheld Tallying Retrofitting}

Handheld tallying retrofitting mainly related to set up the RFID stack label and deploy handsets to warehouse keepers. Port area is divided into different stacks, and placed RFID stack label in each stack, corresponding RFID label with stack in the port management system, so that RFID stack label can correspond the stack uniquely. Tallymen are equipped with handsets. When vehicle prepares for operation, Tallymen can get the vehicle information and operation information that handset read from RFID tag associated with. Then Tallymen leading vehicle arrive at the specified stack that beginning loading or unloading operations. Using the handset read the stack information associated with RFID stack label, allowing vehicle start process. Port management system will record this vehicle that is in queuing. If the length of queuing exceeds limits, port management system will open a new loadometer. After complete operation, tallymen change the vehicle state with handsets and permit vehicles to carry out the next step in the workflow. Then port management system will record this vehicle that is out of queuing. If the length of queuing is below the limits, port management system will close a serving loadometer.

\section{Case Study}

This case study established on collaboration with XSSCL port (Anonymous name). XSSCL Port is subsidiary of a leading world port in the south of China. It's the busiest bulk port of the area of Pearl Delta Region in China. Every year, more than 1,000 vessels transport over 30 million tons of bulk cargo to or departure XSSCL port. About 530 thousand internal vehicle and external vehicle pass in and out port and weighted by loadometers. It takes 1 minute for manual inspection (for both inbound and outbound) and about 40 seconds for weigh vehicle's weight (for both empty weight and heavy weight). XSSCL port faces the same problems we present in section 3. So we propose that XSSCL port upgrades their devices with our suggestion.

\subsection{RFID Hardware Selection}

There are 3 set of RFID handsets considered in this case study. Only one set of them will be used in the case study. It is necessary to find a balance between cost and read range. The specifications of different handsets are listed in the Table 2.

Table 2. Comparison of Different RFID Handsets

\begin{tabular}{|c|c|c|c|}
\hline & $\mathrm{C} 5000 \mathrm{U}$ & AT-570 & XC2903 \\
\hline Distance & $2 \mathrm{~m}$ & $2 \mathrm{~m}$ & $2.5 \mathrm{~m}$ \\
\hline Frequency & 840 960 MHz & 920.5 924.5 MHz & $865 \sim 925 \mathrm{MHz}$ \\
\hline Communication mode & $\begin{array}{c}\text { IEEE802.11 b/g } \\
\text { GSM/GPRS } \\
\text { Bluetooth }\end{array}$ & $\begin{array}{c}\text { IEEE } 802.11 \mathrm{~b} / \mathrm{g} \\
\text { GSM/GPRS }\end{array}$ & $\begin{array}{c}\text { IEEE802.11 b/g } \\
\text { GSM/GPRS } \\
\text { Bluetooth }\end{array}$ \\
\hline Operating temperature & $-20 \sim 50^{\circ} \mathrm{C}$ & $-20 \sim 50{ }^{\circ} \mathrm{C}$ & $-20 \sim 60^{\circ} \mathrm{C}$ \\
\hline Weight & $500 \mathrm{~g}$ & $780 \mathrm{~g}$ & $400 \mathrm{~g}$ \\
\hline Dimensions & $18.65 \times 7.5 \times 4.8 \mathrm{~cm}$ & $17.5 \times 7.6 \times 2.3 \mathrm{~cm}$ & $18.9 \times 8.5 \times 4 \mathrm{~cm}$ \\
\hline Power & $3.7 \mathrm{~V} / 4000 \mathrm{mAH}$ & $3.7 \mathrm{~V} / 4400 \mathrm{mAH}$ & $5 \mathrm{~V} / 4 \mathrm{~A}$ \\
\hline Protocols & ISO18000-6C & ISO18000-6B/6C & ISO18000-6C \\
\hline Price( $(Y, C N Y)$ & 18,000 & 15,000 & 14,000 \\
\hline
\end{tabular}


These handsets have many factors in common. All the three handsets operate at Ultra High Frequency. The read range of all the handsets is quite similar, although XC2903 has $0.5 \mathrm{~m}$ advantages. Operating temperature is another important determinant that all three handsets are also similar. Every handset can operate normally between $-20 \sim 50{ }^{\circ} \mathrm{C}$ and XC2903 can even work under $60{ }^{\circ} \mathrm{C}$. That can adopt all the outdoor temperatures in south of China. The $\mathrm{C} 5000 \mathrm{U}$ has an average performance but it is the most expensive. AT-570 equips largecapacity battery that provide more operating and standby time, the disadvantage is that it is too heavy. Among these three handsets, the range of XC2903 is longest, the price of XC2903 is cheapest and the size and weight of XC2903 is acceptable. So we select XC2903 as the model of handset.

Correspondingly, we select the XC-RF811 RFID reader that it is made by same company. We using ISO18000-6C protocol that both handset and reader work on.

\subsection{Application and Preliminary Result}

XSSCL port has 2 entrances and 11 loadometers. We built a basically covered wireless networks that conclude 8 APs and 32RRHs. All equipment can transfer data by using wireless networks. That improves the type efficiency and keeps the information accurate. There are some statistic results that listed in Table 3 and 4.

Table 3. Partial Weighing Records with using Unattended Loadometers

\begin{tabular}{cccc}
\hline EPCglobal number & Enter time & Departure time & Weight $(\mathrm{kg})$ \\
\hline E2006003141FA801 & $00: 00: 15$ & $00: 01: 12$ & 38500 \\
E2006003141E2C48 & $00: 01: 16$ & $00: 02: 28$ & 39620 \\
E2006003141E8B5B & $00: 02: 34$ & $00: 03: 40$ & 38240 \\
E2006003141E5393 & $00: 04: 07$ & $00: 05: 00$ & 39060 \\
E2006003141F0DE2 & $00: 05: 02$ & $00: 05: 53$ & 43700 \\
E2006003141F18B5 & $00: 08: 24$ & $00: 09: 19$ & 39660 \\
E2006003141F3993 & $00: 11: 44$ & $00: 12: 55$ & 37300 \\
E2006003141EB049 & $00: 13: 23$ & $00: 14: 34$ & 38720 \\
E2006003141F6596 & $00: 14: 39$ & $00: 15: 44$ & 36320 \\
$\ldots$ & $\ldots$ & $\ldots$ & $\ldots$ \\
E2006003141F6596 & $23: 01: 17$ & $23: 03: 05$ & 36900 \\
\hline
\end{tabular}

As Table 3 shows, it takes 1.4 minutes to weight every vehicle in average i.e., the service ratio is $\mu=42.8$ vehicles/h. The improvements provide more than $185 \%$ efficiency. Using EPCglobal number with ceramics RFID tag can identify vehicle accurately and rapidly. 
Table 4. Calculated Arrival Ratio with Intelligent Barriers and Port Management System

\begin{tabular}{c|ccccccc}
\hline & August 1 & August 2 & August 3 & August 4 & August 5 & August 6 & August 7 \\
\hline $\begin{array}{c}\text { arrival ratio } \\
\text { (vehicles/h) }\end{array}$ & 36.9 & 30.3 & 21.0 & 16.0 & 30.0 & 33.8 & 36.0 \\
\hline
\end{tabular}

With these parameters, port management system calculated the allocation of loadometers as Table 5 shows. The actual situation list behind correspondingly.

Table 5. Allocation Result with using Optimization Solution and M/M/n Queuing Model

\begin{tabular}{c|ccccccc}
\hline & August 1 & August 2 & August 3 & August 4 & August 5 & August 6 & August 7 \\
\hline $\begin{array}{c}\text { Calculated } \\
\text { allocation result }\end{array}$ & $4 / 5$ & $4 / 5$ & 3 & 3 & $2 / 3$ & 4 & 4 \\
\hline Actual situation & 5 & 4 & 4 & 3 & 3 & 4 & 4 \\
\hline
\end{tabular}

Except the result calculated in August 3, the allocation results can adapt to the actual situations. In August 3, there was a loadometer temporarily opened just for a special vessel. In other days, the $\mathrm{M} / \mathrm{M} / \mathrm{n}$ model with optimization solution can get a better allocation than before.

\section{Conclusion}

Vehicle transit activity of bulk port is complex and crucial. Any congestion in process will reduce the overall efficiency, even cause serious consequences. Loadometers allocation is one of the most important links. Avoid congestion is the main objective in loadometers. With using $\mathrm{M} / \mathrm{M} / \mathrm{n}$ queuing model calculate allocation results like previous, deviations are found hysteresis and handling less efficiently. In this paper, we propose a solution for loadometers allocation in bulk port with Internet of Things. With using RFID readers, ceramics tags, handsets etc., we propose an upgrade scenario of devices. We cooperate with XSSCL port and take a case study. These efforts reduce more than $60 \%$ extra time on manual inspection and weighing as a preliminary result. Furthermore, collecting and calculating dynamic arrival ratio and service ratio make allocation results more accurate. We believe that as the processes gradually mature, this proportion will increase as we expect. In addition, we will improve the algorithm of loadometers allocation in future.

\section{Acknowledgements}

This research is supported by the Natural Science Foundation of China under Grant Nos. 71132008.

\section{References}

[1] R. Angeles, "RFID technologies: supply-chain applications and implementation issues", Information Systems Management, vol. 22, no. 1, (2005), pp. 51-65.

[2] R. Angeles, "RFID critical success factors and system deployment outcomes as mitigated by IT infrastructure integration and supply chain process integration", International Journal of Value Chain Management, (2012).

[3] U. S. Bugaric, D. B. Petrovic, Z. V. Jeli and D. V. Petrovic, "Optimal utilization of the terminal for bulk cargo unloading”, Simulation, vol. 88, no. 12, (2012), pp. 1508-1521. 
[4] U. Bugaric, D. Petrovic, Z. Petrovic, M. Pajcin and G. Markovic-Petrovic, "Determining the capacity of unloading bulk cargo terminal using queuing theory", Strojniški vestnik-Journal of Mechanical Engi., (2011).

[5] H. K. Chow, K. L. Choy and W. B. Lee, "A dynamic logistics process knowledge-based system-An RFID multi-agent approach", Knowledge-Based Systems, vol. 20, no. 4, (2007), pp. 357-372.

[6] J. Holmström, R. Kajosaari, K. Främling and E. Langius, "Roadmap to tracking based business and intelligent products", Computers in Industry, vol. 60, no. 3, (2009), pp. 229-233.

[7] R. Jedermann, C. Behrens, D. Westphal and W. Lang, "Applying autonomous sensor systems in logisticsCombining sensor networks", RFIDs and software agents. Sensors and Actuators A: Physical, vol. 132, no. 1 , (2006).

[8] X. Jingjing and L. Dong, "Queuing Models to Improve Port Terminal Handling Service", Systems Engineering Procedia, vol. 4, (2012), pp. 345-351.

[9] P. Legato and R. M. Mazza, "Berth planning and resources optimization at a container terminal via discrete event simulation", European Journal of Operational Research, vol. 133, no. 3, (2001), pp. 537-547.

[10] J. Leung, S.C. Chu and W. Cheung, "Design Research Guidelines for Mindful IT Innovations: The Case of RFID Innovation in Supply Chain Management”, System Sciences (HICSS), 2013 46th Hawaii International, (2013).

[11] S. Li, J. K. Visich, B. M. Khumawala and C. Zhang, "Radio frequency identification technology: applications, technical challenges and strategies", Sensor Review, vol. 26, no. 3, (2006), pp. 193-202.

[12] Y. F. Li and B. Jiang, "Examination of the Internet Things Used in Port Information System Construction", Science Technology and Industrial, Qingdao, vol. 10, no. 008, (2010), pp. 29-32.

[13] D. Mullen, "The application of RFID technology in a Port", Port Technology International, vol. 22, (2005), pp. 181-182.

[14] S. Munisamy, "Timber terminal capacity planning through queuing theory", Maritime Economics \& Logistics, vol. 12, no. 2, (2010), pp. 147-161.

[15] K. G. Murty, J. Liu, Y. W. Wan and R. Linn, "A decision support system for operations in a container terminal”, Decision Support Systems, Amsterdam Netherlands, vol. 39, no. 3, (2005), pp. 309-332.

[16] D. J. Robb, B. Xie and T. Arthanari, "Supply chain and operations practice and performance in Chinese furniture manufacturing", International journal of production economics, vol. 112, no. 2, (2008), pp. 683699.

[17] A. Sarac, N. Absi and S. Dauzère-Pérès, "A literature review on the impact of RFID technologies on supply chain management", International Journal of Production Economics, vol. 128, no. 1, (2010), pp. 77-95.

[18] X. Shi, D. Tao and S. Voß, "RFID technology and its application to port-based container logistics", Journal of Organizational Computing and Electronic Commerce, vol. 21, no. 4, (2011), pp. 332-347.

[19] J. K. Siror, S. Huanye and W. Dong, "RFID based model for an intelligent port", Computers in Industry, vol. 62, no. 8, (2011), pp. 795-810.

[20] X. Song and L. Huang, "Business Process Optimization and System Design of Bulk Port Truck Delivery Based on Internet of Things", Logistics Technology, Xiangfan Hubei, vol. Z2, (2010), pp. 178-181.

[21] X. Song, L. Huang and S. Fenz, "Internet of Things Applications in Bulk Shipping Logistics: Problems and Potential Solutions", Internet of Things, Springer Berlin Heidelberg, (2012), pp. 565-571.

[22] S. L. Ting, L. X. Wang and W. H. Ip, "A study on RFID adoption for vehicle tracking in container terminal", Journal of Industrial Engineering and Management, vol. 5, no. 1, (2012), pp. 22-52.

[23] A. Ustundag and M. Tanyas, "The impacts of radio frequency identification (RFID) technology on supply chain costs", Transportation Research Part E: Logistics and Transportation Review, vol. 45, no. 1, (2009), pp. 29-38.

[24] P. Valckenaers, B. S. Germain, P. Verstraete, J. Van Belle and H. Van Brussel, "Intelligent products: agere versus essere", Computers in Industry, vol. 60, no. 3, (2009), pp. 217-228.

[25] W. Wang, Y. Yuan, X. Wang and N. Archer, "RFID implementation issues in China: Shanghai port case study”, Journal of Internet commerce, vol. 5, no. 4, (2006), pp. 89-103. 
International Journal of Grid and Distributed Computing Vol.7, No.1 (2014) 